\title{
Black economic empowerment in the South African mining industry: A case study of Exxaro Limited
}

\author{
A. Fauconnier and B. Mathur-Helm* \\ University of Stellenbosch Business School, \\ PO Box 610, Bellville 7535, Republic of South Africa \\ babita@usb.ac.za
}

Received September 2008

\begin{abstract}
This paper explores some of the key challenges and opportunities in the implementation of the broad-based black economic empowerment (BBBEE) deal of Kumba Resources, which subsequently led to the formation of Exxaro Limited, a large black-owned mining conglomerate in South Africa. Qualitative data were collected through in-depth interviews with a sample of 11 leaders involved directly in the deal. The data were content-analysed and the findings suggested that BEE transactions faced numerous challenges, including finding sustainable funding, securing suitable investors, merging various cultures, dealing with fronting and leadership, and planning management and leadership succession. The study concluded that the deal led successfully to both the equitable transfer of ownership and management and to the control of financial and economic resources to a wider base of the black population. However, several malpractices were identified which may have impeded the process of achieving the intended outcomes. The article provides recommendations, indicates limitations and proposes a way forward.
\end{abstract}

*To whom all correspondence should be addressed.

\section{Introduction}

The government of South Africa (SA) implemented broadbased black economic empowerment (BBBEE) as a nationbuilding strategy. The act intends to empower 'all blacks' listed as Africans, Coloureds and Indians. The strategy is based on the Broad-Based Black Economic Empowerment Act No. 53 of 2003 in conjunction with its Associated Charters, the Codes of Good Practice and various Scorecards. Initially South African companies used the narrow-based black economic empowerment (BEE) criteria or the draft phase 1 of the Codes, and, as a result of nonalignment of the Preferential Procurement Policy Framework Act, several private and government organisations still use the narrow-based approach. However, the implementation of the broad-based economic empowerment (BBBEE) of the Codes has introduced new ways of defining and measuring BEE, which has led to contemplation in the companies comparative BEE rankings (Grobler, 2006). Grobler (2006) suggests that in comparison to their narrow-based versions, the broad-based Codes and the Sector Charters not only encourage and formalise broadbased empowerment, but they also place more emphasis on the inclusion and participation of women and new sector players, besides accentuating broad-based structures and financial sustainability. Hence, contrary to some claims about the 'failure of BEE' (Slaughter, 1999; Sono, 1999; Turok, 2000), a multiracial middle class, including a black capitalist class, has begun to emerge over the last decade in South Africa (Iheduru, 2004). The emergence of the black bourgeoisie may indeed be occurring at much faster rate; however what is not clear is the likelihood of this class being able to push for the enactment and successful implementation of the BEE strategies (Iheduru, 2004).
Simultaneously, BEE dealings which meet the demanding expectations of government and society within the realities of business are not easy. They are relatively low in success rate, signifying a paradox between the accuracy about such transactions and the government policy. Besides, a BEE deal can create instability and lead to a great deal of turbulence in the business sector. One of the reasons for this is that certain BEE parties acquire shares in various companies, while others move into short-term business opportunities (Turok, 2006). Secondly, access to the large amounts of capital required for such deals is sometimes a major concern as most of these transactions take place in the open market without government's involvement, not even in the selection of partners (Fauconnier, 2006). Although, anecdotal evidence suggests some common problems that could contribute to the failure of many such deals (Fauconnier, 2006), no empirical study could be found to validate these claims and conclude exact reasons.

The present study is exploratory in nature and aims to contribute to the literature by attempting to address the gap in BEE dealings, the challenges and the factors for the achievement of success - which are currently unavailable in the literature. The aim is to explore the contexts of theory and practice of BEE transactions by examining the case of the resultant company Exxaro Limited to investigate the following: challenges faced by all parties during the BBBEE transaction; positive aspects of the transaction; current and future challenges for Exxaro Limited; and plans to address them to ensure sustainability and the successful completion of the deal. 


\section{Aim of the study}

The present study aims to explore the unique experience of the leaders and decision-makers in the Kumba Resources BEE transaction and the formation of Exxaro Limited, and examines the challenges faced, and success factors experienced during and after the deal.

\section{Black Economic Empowerment}

Black Economic Empowerment (BEE), or the narrow-based approach, came into existence in 1994, when South Africa elected its first democratic government. This was followed by the establishment of the Broad-Based Black Economic Empowerment (BBBEE) Commission in 1999 and the subsequent strategies and policies to increase black ownership of businesses and to accelerate black representation in management (Booysen, 2007). While in 1990 black people occupied 3\% of the corporate management positions (Gray \& Karp, 1993), in 1995 they owned only $1 \%$ of the total market value of the Johannesburg Stock Exchange (Cargill, 1999).

Although BEE is not affirmative action as such, employment equity forms part of it (Republic of South Africa, 2007a). BEE was introduced not only to redress the imbalances of the past, but also to implement a growth strategy aimed at realising the country's full economic potential, increasing the skills levels, creating more jobs, and reducing poverty in a short period of time without redistribution of existing wealth (Republic of South Africa, 2007b). Iheduru (2004) hence argues that strategically the black bourgeoisie integration would also foster the creation of a successful capitalist economy in South Africa.

The broad-based or the second phase of BEE was introduced because the narrow-based or the first-phase approach was found to limit the set objectives. For instance, in 2003, 60\% of the empowerment deals amounting to R25.3 billion went to the companies of only two black businessmen (Kovacevic, 2007). Kovacevic (2007) argued that although BEE professes to promote the meaningful participation of black people in the economy, it actually fosters a political cronyism that benefits only a few elites. Moreover, the BEE initiative, although an empowerment incentive, is an inadequate means of extending prosperity (Kovacevic, 2007), while further widening the income disparity within the black population.

Similarly, Du Toit, Krugar and Ponte (2008), in their study on BEE in South Africa's wine industry, indicate that while BEE has potentially provided a whole new spectrum of possibilities to established industries, the system of monitoring and verification proposed by government and the industry charters is technocratic and favours individuals rather than workers collectively or their communities. Although this might have been the case with the narrowbased (BEE) approach, it could have been avoided by the use of broad-based BEE.

For the meaningful and sustainable implementation of BBBEE and its measurement across all sectors of the economy, the Department of Trade and Industry implemented the Codes of Good Practice in 2007, providing guidelines as a standard framework to ensure that no industry is disadvantaged in relation to another when presenting its broad-based credentials, and that all businesses and industries work towards a long-term plan for economic transformation that is measurable and realistic for all stakeholders (Department of Trade and Industry, 2004). Therefore companies employing BBBEE are committed to finding common ground between their own specific industry charters and the Department of Trade and Industries (DTI) Codes.

Various BEE deals that have taken place over the past decade, 1996 to 2006, have their value shown in Figure 3 below.

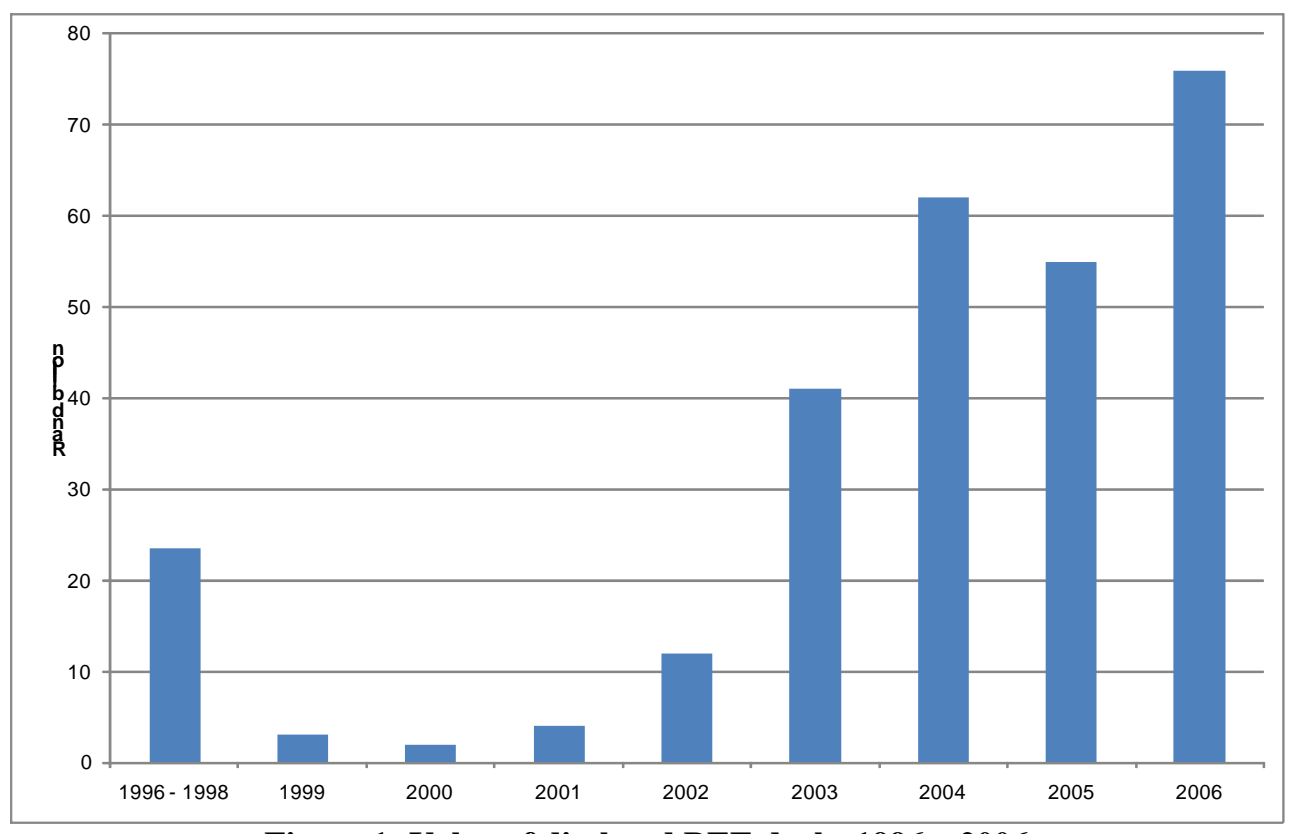

Figure 1: Value of disclosed BEE deals, 1996 - 2006

Source: Business Map Foundation, 2007. 
The Business Map Foundation (2006) recorded 350 BEE deals in 2005, compared to some 250 deals in 2004. In 2004 there were several very large deals, whereas in 2005 there were more deals with a lower average rand value (Business Map Foundation, 2006). Figure 1 shows an apparent reduction in BEE deals in value only, hence although the R55 billion in 2005 is a significant figure, it does not indicate the BEE activities in full scale. Furthermore, in a number of transactions the value of stakes bought by black investors was not disclosed (Business Map Foundation, 2006). For example, in 2006 approximately 317 BEE deals were announced with only about 173 of them disclosing the value of their transaction (Business Map Foundation, 2007). These 173 deals represent approximately R75 billion, which is a notable increase from 2005.

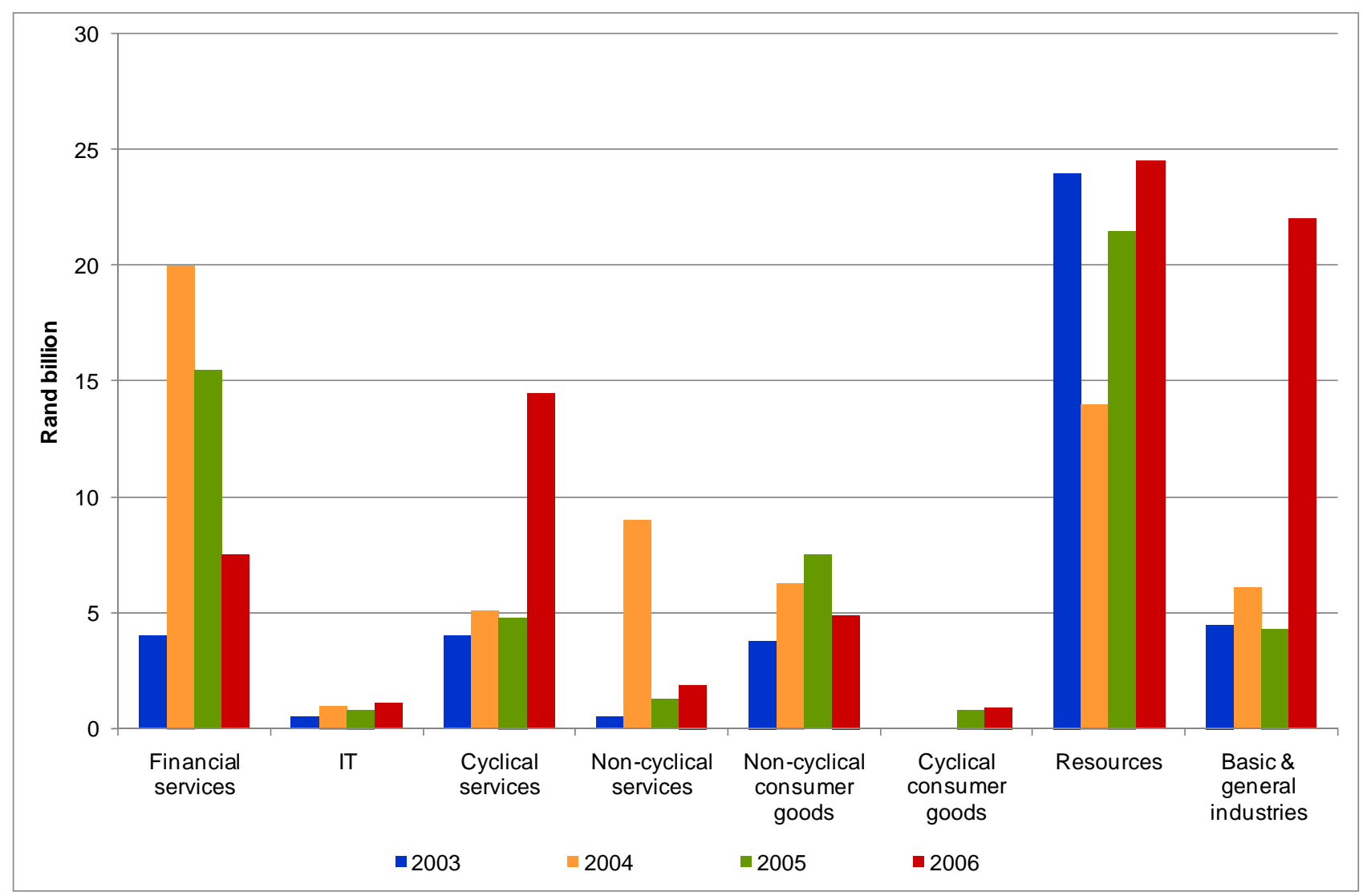

Figure 2: BEE deal activity by sector for 2003 - 2006

Source: Business Map Foundation, 2007.

Figure 2 shows that the Resources sector has been on the forefront of BEE deals since the Broad-Based SocioEconomic Empowerment Charter for the South African Mining Industry was introduced in 2003. The financial, resources and industrial sectors generally tend to disclose their values, as a large number of these companies are listed and operate under strict corporate governance procedures (Business Map Foundation, 2007).

\section{The Generic Scorecard and its seven elements}

The BBBEE expectations from the Department of Trade and Industry's (2004) perspective and scorecard recognition is determined by the contribution of businesses to broad-based $\mathrm{BEE}$ and the business leaders buying into the national agenda, across the seven elements of: ownership, management, employment equity, skills development, procurement, enterprise development and socio-economic development (Balshaw \& Goldberg, 2005). These seven elements combine on a weighted scale, which is known as the Generic Scorecard. This Generic Scorecard is a tool used to systematically quantify the extent to which a company is BBBEE compliant.

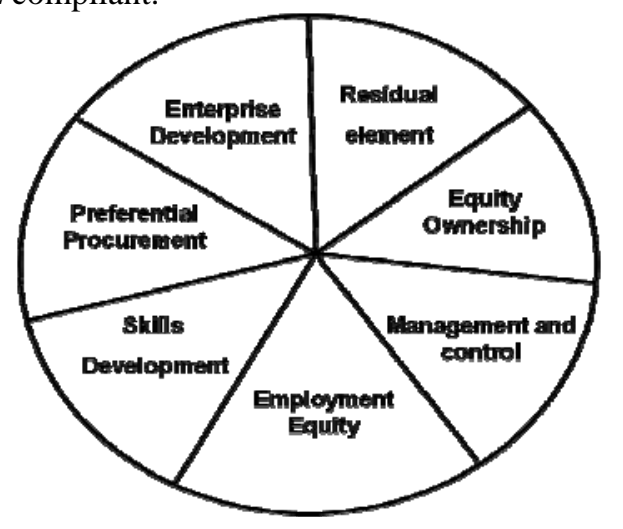

Figure 3: Seven elements of the Generic Scorecard Source: Department of Trade and Industry, 2004.

BBBEE applies to all enterprises that conduct a business, trade or profession in South Africa, whether they are companies, sole proprietors, cooperatives, multinationals, 
enterprises owned by state organisations or public entities. Moreover, the codes requirements apply equally to whiteand black-owned and controlled enterprises.

According to the Department of Trade and Industry (2004), Section 12 of the BBBEE Act has made provision for sectors to develop their own industry-specific transformation charters. The charter enables specific sectors to build sector-wide commitment to BBBEE, including undertakings by both government and the private sectors to implement measures to fast-track BBBEE.

\section{South Africa's key empowerment charters}

The development of industry-specific black economic empowerment (BEE) charters in South Africa is an empowerment framework for the country's specific industries, including the mining industry, petroleum and liquid fuels industry, the maritime, tourism and financial services, the ICT industry, and the construction sector. Each charter is tailored to suit a particular industry and generally stipulates a target of $25 \%$ black ownership over the next 10 years (Department of Trade and Industry, 2004). In the current empowerment legislation, the mining industry and the petroleum and fuel industry charters are placed to provide a framework for a systematic and continuous empowerment of the historically disadvantaged South Africans in these industries.

\section{Mining industry charter}

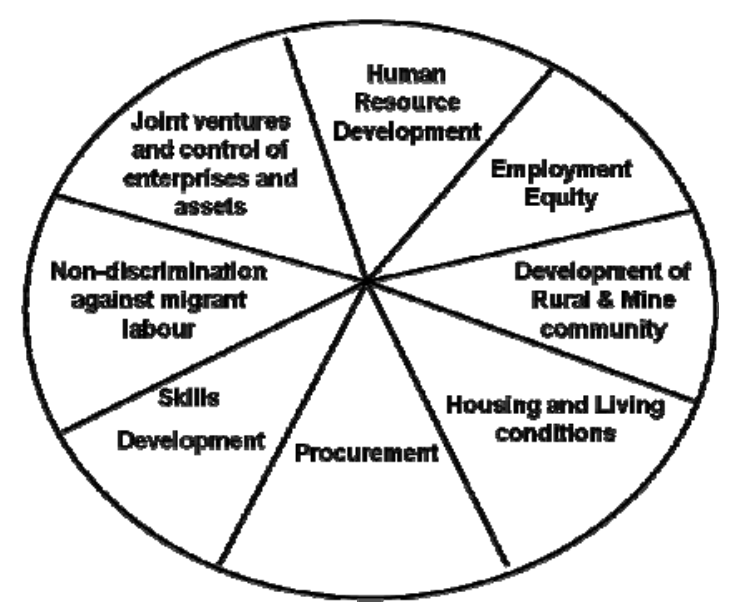

Figure 4: Eight elements of the Mining Industry Charter Source: Department of Trade and Industry, 2002.

Figure 4 shows criteria of the charter, namely Ownership, Joint ventures and control of enterprises and assets; Human resource development; Employment equity; Nondiscrimination against migrant labour; Development of rural and mine community; Housing and living conditions; Procurement; Skills development (Department of Trade and Industry, 2004; Republic of South Africa, 2002).

In 2002, the Department of Minerals and Energy (DME) introduced the Broad-Based Socio-Economic Empowerment Charter for South Africa's Mining Industry, with the aim to:
- promote equitable access to the nation's mineral resources to all the people of South Africa;

- $\quad$ substantially and meaningfully expand opportunities for historically disadvantaged South Africans (HDSA), including women, to enter the mining and minerals industry and to benefit from the exploitation of the nation's mineral resources;

- $\quad$ utilise the existing skills base for the empowerment of the historically disadvantaged South Africans;

- expand the skills base of HDSA in order to serve the community;

- promote employment and advance the social and economic welfare of mining communities and the major labour distribution areas; and

- promote beneficiation of South Africa's mineral commodities (Republic of South Africa, 2002).

The objective of the Mining Industry Charter was to achieve $26 \%$ ownership of the previously disadvantaged people in the mining companies by 2012. The charter provides a framework to help the mining companies to comply with the Mineral and Petroleum Resources Development Act, which obliges them to promote black economic empowerment when applying for the new mineral rights or converting current rights. A key component of the charter is the mining scorecard, which sets out standards for measuring the BBBEE process in the sector. The charter has similarities with, and is based on, the generic scorecard as proposed in the Codes of Good Practice issued by the department of trade and industry (Department of Trade and Industry, 2004). Although it needs to be aligned to the generic scorecard as a way forward, this is as yet not aligned with the codes and is not the same, despite similarities.

The scorecard is the main tool for setting transformation standards against which individual enterprises are measured. The charter commits government, industry and labour, to planning mechanisms to enable businesses to achieve their BBBEE targets, and to set out sector specific scorecards. These undertakings are listed in the Mining Industry Charter (Department of Trade and Industry, 2004).

\section{BEE transaction of Kumba Resources and the forming of Exxaro Limited}

The formation of Exxaro Limited is an example of a BBBEE transaction of a mining industry which became one of the largest black-owned, black-controlled and blackmanaged companies in South Africa, with a market capitalisation of R16 billion when it was formed in November 2006 and first listed on the Johannesburg Stock Exchange (JSE) (Republic of South Africa, 2007b). However this transaction faced several challenges.

Kumba Resources Limited, one of South Africa's largest diversified mining companies with a market capitalisation of R34.6 billion (Kumba Resources, 2006), was spun-off from Iscor in 2001 and had interests in iron ore, coal, heavy 
minerals and zinc (Kumba Resources, 2006). In 2003, Anglo American plc acquired more than $35 \%$ of Kumba Resources shares and was forced to make a mandatory offer for the remaining shares in Kumba Resources. Although Anglo American plc gave a verbal undertaking to the South African government to maintain its shareholding below $49 \%$, the rand strengthened during the offer period leading to more shareholders than expected accepting the Anglo American plc mandatory offer (Kumba Resources, 2006). This resulted in Anglo American plc owning 66\% of Kumba Resources shares and becoming the major shareholder of the company. Subsequently, it lead to conflict of interests as Kumba Resources and Anglo American plc had overlapping interests in coal, zinc and heavy minerals (Kumba Resources, 2006).

While Kumba Resources was committed to finding common ground between the mining industry's charter and the DTI's codes, its strategy was to become truly representative of South Africa's demographics, and to build a credible empowerment base and position itself as a constructive roleplayer in the transformation and development of the South African mining industry. Hence it embraced the BBBEE strategy.

In October 2005, Kumba Resources, Anglo American plc and Eyesizwe Mining announced the ingress of Kumba Resources into a Transaction Framework Agreement, through which the relevant parties embarked on a series of transactions that resulted in the unbundling and separate listing of Kumba Iron Ore and the transfer of a controlling interest in Kumba Resources to Exxaro, a black-owned and black-controlled company, by means of a fully funded and sustainable transaction (Kumba Resources, 2006).

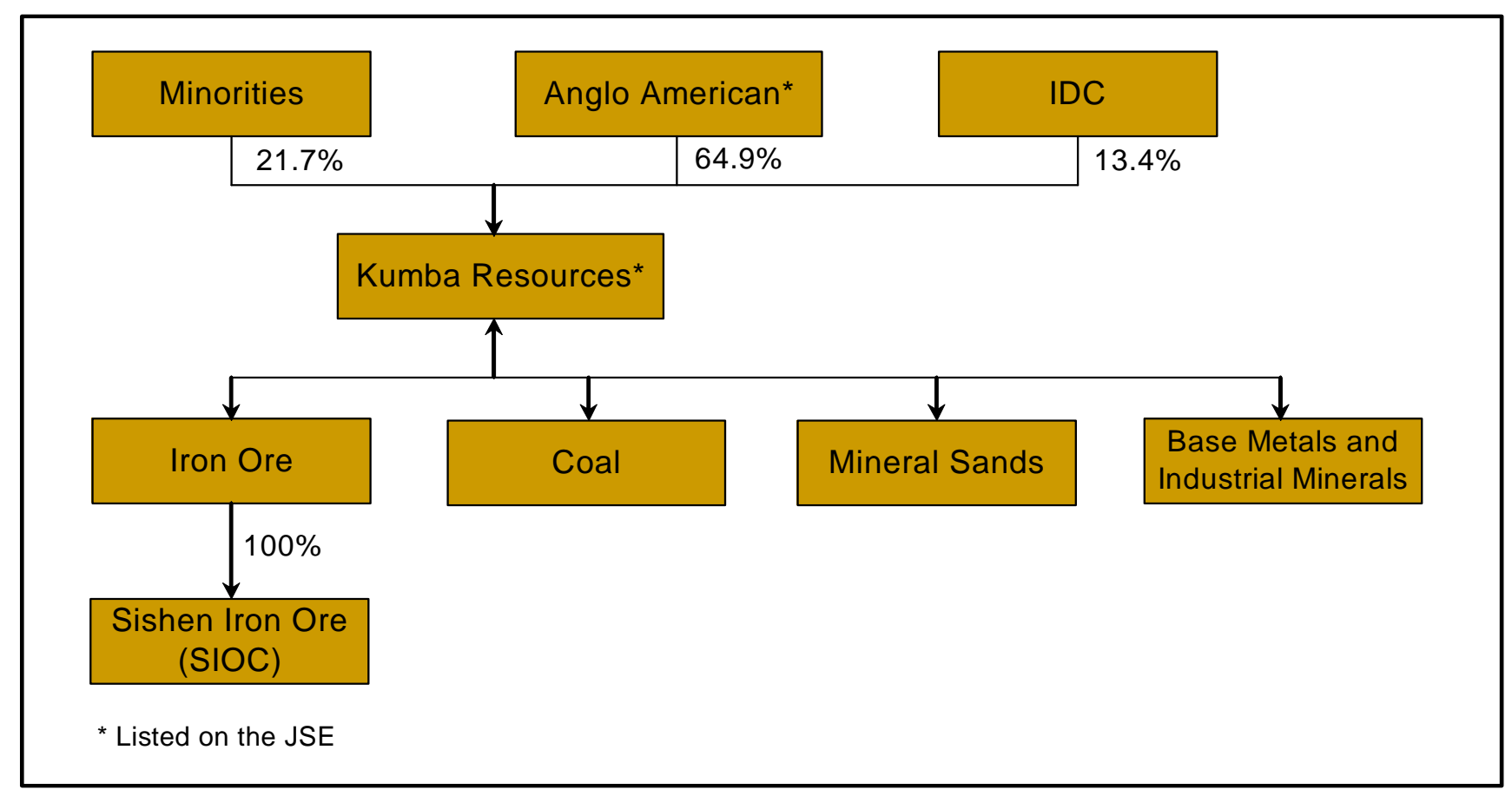

Figure 5: Kumba Resources structure before the unbundling in 2006

Source: Kumba Resources, 2006. 


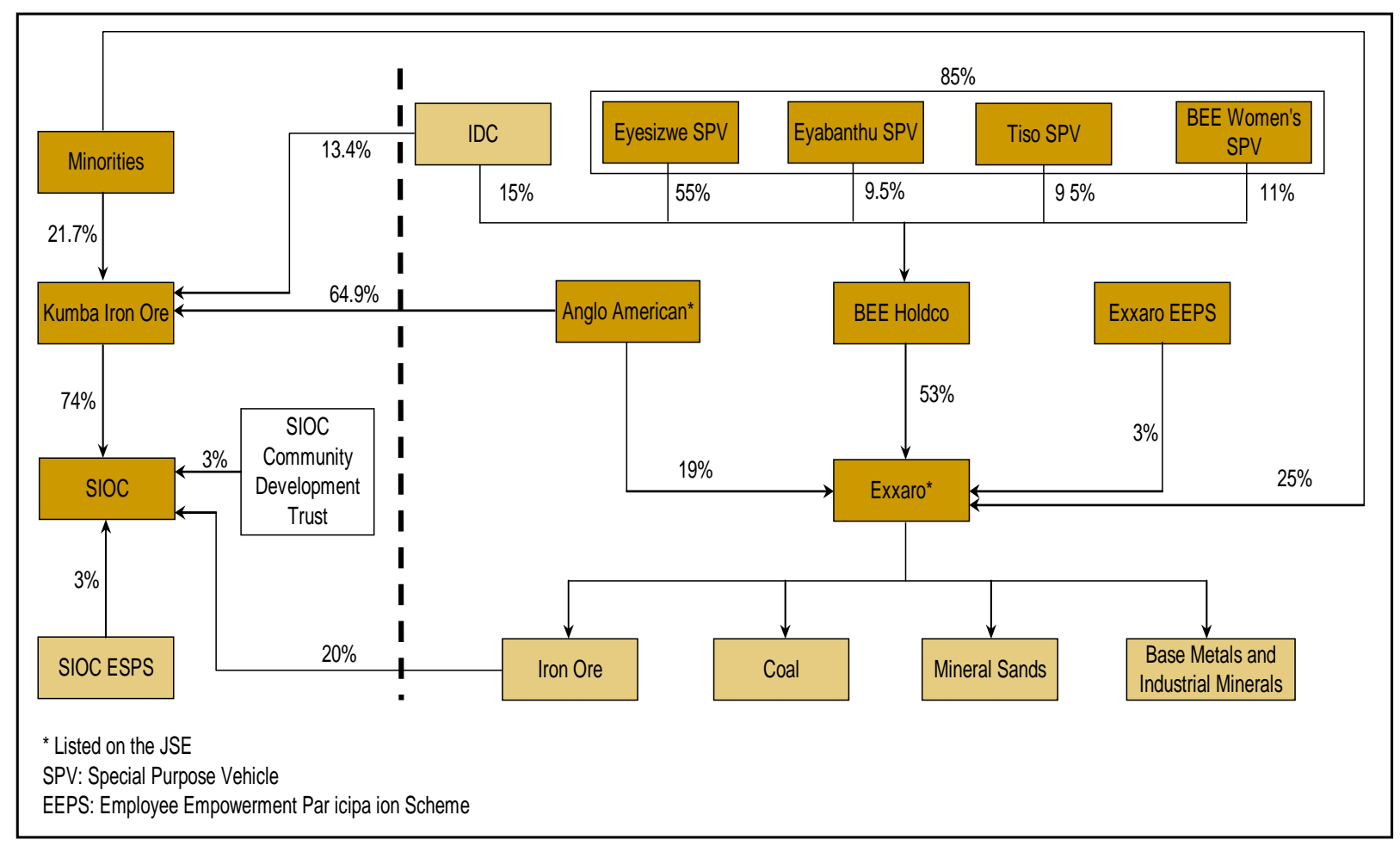

Figure 6: Exxaro Limited structure, after the unbundling of Kumba Resources

Source: Kumba Resources, 2006. While Figure 5 illustrates the structure of Kumba Resources before its unbundling in 2006, Figure 6 illustrates the structure of Exxaro Limited, a company formed as a consequence of the unbundling. The BEE partners involved in Exxaro Limited were Eyesizwe SPV, Eyabanthu Consortium, Tiso Consortium, BEE Women's Group and Sishen Iron Ore Company (SIOC) Community Development Trust. Figure 6 shows that they are the prime shareholders of the newly formed company.

\section{Methodology}

\section{Sample}

The study aimed to investigate and establish challenges faced during the BEE transaction of Exxaro Limited, as well as how these challenges were addressed. Therefore the sample was carefully selected - after the detailed examination of individuals from a group of senior representatives who were directly involved in the Exxaro Limited transaction - to share their experiences, rather than to represent a large group.

The sample consisted of 11 individuals representing 23\% of the population of the total number of representatives from Anglo American South Africa, the former Kumba Resources, Eyesizwe Mining, Tiso Consortium, Eyabanthu Consortium, South Africa Women in Mining Association (SAWIMA), Industrial Development Corporation (IDC), Chamber of Mines, Deutsche Bank, Rand Merchant Bank (RMB) and government, more specifically the Department of Minerals and Energy (DME).

\section{Data collection method}

Data were obtained through the semi-structured, open-ended and in-depth interview method as the purpose was to cover certain themes. This method allows freedom to further explore themes and questions emerging from the interviews and to give the interviewee an opportunity to offer information outside the initial themes and questions posed.

\section{Interviews}

Interviewees were personally contacted by one of the authors and were invited to volunteer to participate in the research. The objectives of the study were explained and interviewees were assured that the data would be treated with confidentiality. All interviewees who were approached agreed to participate. The aim was to obtain in-depth information through semi-structured interviews, and the sample was at liberty to convey any information other than that requested. The interviews were conducted at a time and place suitable to the interviewees and lasted approximately one hour to one and a half hours.

\section{Analysis strategy}

The method of content analysis was used to analyse the qualitative data obtained. This method enables the occurrence of specific terms or concepts in a text or set texts to be determined and for the meaning of such content in a given context to be inferred. The method also allows openended questions to be coded, through disclosing differences in communication, determining the psychological state of sample groups and identifying reflections of cultural patterns within individuals, groups and societies (Weber, 1990). The content analysis method was a practical and descriptive tool to investigate the experiences of the given sample group. The qualitative data obtained were used only in the descriptive sense to explore the problems and challenges faced during BEE transactions by the senior representatives, and not for testing any specific hypotheses or statistical inferences. 


\section{Categories for content analysis}

The interview questions were classified under the following seven categories for content analysis:

Category A: Main challenges encountered during the transaction. The questions for this category were designed to investigate the major problems and challenges encountered by all parties during the transaction.

Category B: Processes and methods used to overcome the main challenges. Questions for this category were designed to investigate the processes and methods used by the various parties to overcome the challenges and problems faced during the transaction.

Category C: Sustainability issues. The design of the questions for this category focused on the exploration of sustainability issues of a transaction of this magnitude.

Category D: Positive aspects. Questions for this category were designed to explore the positive aspects and the things that went well during the transaction.

Category E: Current issues. For this category the questions were formulated to investigate the challenges currently faced by Exxaro Limited, after conclusion of the deal.

Category F: Future challenges. Focus of the questions for this category was on investigating potential challenges for the newly formed company and the link to sustainability.

Category G: Different options. The questions in this category were designed to investigate alternatives to what was done during the transaction and the way that challenges were addressed.

\section{Results}

Category A: Main challenges encountered. For nine respondents, the main challenge was the establishment of an innovative and sustainable funding structure, devised to ensure minimal leakage of value for the shareholders of Kumba Resources and to create wealth for the BEE groups, subsequently becoming shareholders in the new company. Four respondents reported aligning the interests of the various parties involved in the transaction as another challenge.

For the majority the challenge was to ensure that all stakeholders were involved in every step of the transaction, considering the complexity and size of the deal. For one person, determining a base of aligned shareholders who were realistic in their expectations about the risks involved and understanding each party's contribution to the success of the deal was a huge challenge.

For four respondents, ensuring that the empowerment was a broad-based one was a challenge which they had to deal with from the inception of the transaction. For another four individuals, conflicting issues within certain BEE groups needed to be dealt with. According to one individual the challenge was that some of the BEE groups were divided entities with non-aligned interests when they entered into the transaction.

Two individuals stated that finding the right BEE partners and the right combination of partners was a challenge. For one respondent the lock-in period for the BEE partners was a challenge that had to be addressed within the various BEE groups.

The multinational company had developed plans based on its own agenda to obtain certain assets and BEE accreditation, which was being imposed onto the other transaction parties. Hence fitting into their agenda was a huge challenge, according to one respondent.

One person reported that empowerment by definition requires wealth to be transferred from those who own it to people who historically did not have it or lacked the ability to generate it. Hence the problem was that certain BEE investors were only interested in generating wealth for themselves, and not in the sustainability of the new company. And hence establishing an innovative and sustainable funding structure was challenging.

Two respondents stated that it was important that all the parties involved in the deal acknowledged government's requirements and acted upon them. However, the challenge was in broadening the base of empowerment in South Africa and to avoid the "usual suspects" becoming the BEE partners through the transaction.

Category B: Processes and methods used to overcome the main challenges. Four individuals reported that having a comprehensive and transparent process in place for the selection of BEE partners assisted in overcoming some of the challenges.

Three individuals stated that having a good understanding of the needs and requirements of all the parties involved in the transaction and aligning their various interests, assisted in overcoming some of the challenges. One individual stated that since the beginning of the deal, there was clarity about various requirements, needs and expectations from various parties involved, which obviated spending a considerable amount of time on understanding and aligning the needs and expectations of all the parties. Four people stated that studying the background of various parties involved in the transaction, assisted in minimising some of the challenges.

The establishment of a steering committee, regular strategic sessions, regular meetings and ongoing engagement were reported by four respondents as helping in overcoming some of the challenges.

For one person, formation of various work streams within the steering committee and allocation of individuals within the project teams to work with the streams helped a lot. Using the right people with the right skills in concluding the deal was a favourable measure for three individuals.

For over a quarter of the samples, setting up provisional funding was a good means of dealing with main problems, and, for two respondents, ensuring that the assets of the 
various parties were of an acceptable standard and price, was an excellent means of managing certain challenges.

One person reported that good, open, upfront and honest relationships and interaction between various parties and individuals helped greatly.

Category C: Sustainability issues. Almost half of the total sample reported that establishing an innovative and competitive funding structure was an important approach to ensure sustainability of the transaction. According to one respondent, it was important to ensure a strong and sound asset base that could generate a certain cash flow, sustaining the deal, the company and the BEE shareholder funding.

Four individuals reported that to ensure sustainability, it was important to create a diversified mining company with a sound asset base, good growth prospects and an attractive investment case. While, two respondents explained that it was important to bulk up the company to a size with a good mix of commodities that would be sustainable. Almost all respondents stated that, since diversity helps with the cyclical nature of the mining industry, it was important for Exxaro Limited.

Over a quarter samples reported that finding the right BEE partners was important to ensure sustainability of the transaction. One individual reported that it was important to find and appoint a leading BEE partner with hands-on experience in managing mining assets and capabilities of leading the company, while ensuring that the partners could work together.

A quarter of the sample found it important to identify quality leadership, management and succession planning as crucial for sustainability. According to one person, it was important to have representation of suitable quality at management and board levels, in order to instil confidence in people and in the markets, for investment purposes.

Three people stated that a lengthy lock-in period for BEE partners was important for sustainability, as this would ensure that the company kept its broad-based empowerment status, while for one individual, benchmarking and stresstesting against personal and institutionalised experiences helped in the sustainability of the organisation.

Category D: Positive aspects. For more than a quarter of the sample the establishment of an innovative and creative funding structure, along with the associated facilitation and benchmarking exercise, went extremely well. Moreover, one respondent revelled that through clever financial engineering, the debt that needed to be serviced through dividend flow was reduced to acceptable levels.

Although three respondents reported trust relationships as more beneficial between all the parties, for one respondent this was maintained throughout the transaction, especially with the consortium partners.

Three individuals stated that the quality of assets and establishment of a critical mass in terms of the assets was favourable. One respondent stated that the value loss for shareholders of Kumba Resources was minimal and was adequately compensated for by the value creation after the listing of Exxaro Limited and Kumba Iron Ore in 2006.

Three respondents reported that the selection and the combination of the BEE partners were done competently. One person stated that the efficiency of the structures and combination of the consortia were well put together.

Two people stated that creating value for all transaction parties was a positive aspect. For two individuals the highlights were the women's empowerment and community involvement. One person said that the transaction positively contributed towards the capacity-building goal of the country.

Category E: Current issues. Of the total sample, five respondents mentioned that the company growth and value creation for all stakeholders were the main issues since the company's listing. One person explained that the challenge is in growing the company significantly with its vast opportunities, without diluting the empowerment shareholding below 51 percent for a certain period of time.

According to five individuals, leadership, managing succession, transition and handing over (the period between current leadership and the leadership taking over) were the significant concerns. Furthermore they explained that it was difficult to bring people from different perspectives into an organisation as they have different outlooks on business and governance issues.

Four respondents cited operational performance and stability as one of the current challenges that the new company had to deal with. They further stated that only through operational performance and stability could the company deliver on the asset base in a sustainable manner.

One person stated that the new company was in the process of integrating various cultures and operations, but still had to perform to meet the production criteria. Three respondents stated that this creation of South Africa's biggest black-owned and black-managed company had created expectations within the markets and the organisations; hence, dealing with them is a huge challenge. Two individuals reported that understanding the new business and giving coherence and meaning to it is a huge concern.

Of the total sample, two individuals reported that maintaining a sound balance-sheet is currently a challenge for Exxaro Limited and will remain a future challenge. Another two respondents stated that issues within the BEE groups were challenging. For one person the issues that Exxaro Limited is currently facing mirror the social issues faced by South Africa, such as HIV/Aids, social upliftment of the communities, and the current skills shortage, locally and globally.

Category F: Future challenges. Seven respondents reported that growing the company and realising the company's good project pipeline will be a future challenge for Exxaro Limited. According to four respondents, performance and 
efficiency are current and future challenges facing the new company. They state that it is necessary constantly to ensure business profitability through performance and efficiency in terms of costs. However for two people, keeping the company's empowerment status is a huge future challenge.

For over a quarter of the samples, the cyclical nature of the markets and the commodity prices were the future issue. According to one person, Exxaro Limited is dependent on commodity prices and the growth of the Chinese market, as a significant portion of Exxaro's exports goes to China. Furthermore, the transaction was concluded in a bullish market. If there is a downturn in commodity prices and a bear market becomes apparent the share price could be depressed and the high level of gearing could become a problem.

More than a quarter of the samples felt that skills attraction and retention is a current and foreseeable future challenge for Exxaro Limited. Two respondents perceived conversion of the mining rights as an issue that Exxaro Limited will have to grapple with, now and in the future. According to one respondent the inconsistencies within the DME (Department of Minerals and Energy) are problematic for Exxaro Limited, as they cause long delays in the conversion of mining rights, and associated input costs can be extremely high. Most of the mining charter content is vague and requires extensive interpretation. Every provincial department of the DME interprets the charter differently and mining organisations need to adapt to this - especially if the organisation does business in various provinces. This creates a lot of administrative uncertainties for mining companies. What is needed to convert mining rights in one province is not necessarily the same in another province. Furthermore, the DME at national level has its own interpretation of the charter which is not necessarily the same in the various provinces. Obviously this uncertainty can create delays in the conversion of mining rights and it also causes an increase in costs for mining companies.

For one individual, the dividend flow to the BEE partners was a concern. He further stated that the challenge will be to ensure that there is a consistent dividend flow to the shareholders, i.e. the BEE partners, every year without eroding the company's margins.

Category G: Different options. Five respondents said that they would have liked to spend more time on the due diligence of the BEE partners to be assured of the parties' competence and to resolve issues within various BEE groups, as there were several deals and various interests and visions needed to be aligned. For four respondents more time should have been spent on a better understanding of mining legislative processes.

Four respondents believed that only a few BEE partners should have been included in an empowerment transaction of this magnitude. One respondent acknowledged that the broadness of the partnership is a problem in itself as it became unwieldy to work with. For one respondent the communication should have been more proactive and the consortium of shareholders should have been briefed on an ongoing basis. Another respondent also stated that they should have been more proactive in the way they kept government abreast of the progress and decisions of the deal, without allowing its interference in the process.

According to one individual, it was important that all the BEE partners had advisory capacity, although not every empowerment partner had access to top level advisors. In addition, the BEE partners did not have the best advice at all times and certain partners did not have advisory capacity.

\section{Discussions}

The findings are discussed in relation to the previous literature.

Category A: Main challenges encountered. When compared, present findings in the case of Exxaro Limited correlate with the Gold Fields-Mvelaphanda transaction as both transactions required innovative funding structures to ensure the execution of the deals (Business Map Foundation, 2003). The similarities include the use of SPVs, mezzanine financing, issuing of preference shares, and vendor financing. A previous study (Goldwyer, 2007) found that the single most complex element of any empowerment transaction, for both principals and bankers, is related to financing. This is parallel to the results of the present study and is supported by the Gold Fields-Mvela Resources and De Beers-Ponahalo case studies (Business Map Foundation, 2003).

A previous study (Jack, 2006) claimed issues such as aligning the interests of various parties involved in the transaction as a huge challenge. Present results demonstrating the alignment of the interests of the various parties involved in the transaction as a huge challenge is consistent with the study of Jack (2006).

A past study (Ryan, 2006) is consistent with the present results, demonstrating the samples' awareness, understanding and their idea of implementing the government's broad-based BEE in the Exxaro Limited case by notably leaving out the "usual suspects" and dealing with new black business as well as women's groups. The study had claimed that in various major BEE deals, there was a determination to avoid the usual black suspects and to spread the benefits of the empowerment transactions broadly, and this consequently led to new black executive faces appearing in the country's financial media.

The present results and Kingston's Report (Goldwyer, 2007) strongly correlate as they recognise various challenges posed by BEE, one of which pertains to finding the right partners and the right combination of partners, for a BEE deal. Kingston's report further states that the equity weighting between the various groups depends on the details of the empowerment deal, as well as following a thorough, transparent tender process to select partners with objectives that merge with the company ethos.

The present study found that the BEE partners have undertaken not to dispose of their shareholding until the fifth anniversary of the transaction completion date and to remain a historically disadvantaged South African (HDSA) group 
until the final date. This is consistent with the findings of the previous study by Business Map Foundation (2003), stating that while the Gold Fields-Mvela Resources transaction had a similar lock-in period for its BEE partners, Mvelaphanda undertook not to dispose of its empowerment interest in Gold Fields during the five-year lock-in period. The lock-in period was enforced to prevent dilution of the Gold Fields BEE status and to comply with the BEE Codes of Good Practice.

The present study found that the challenge for BEE investors was to fit into the agenda of a multinational company. This is congruent with Jack's (2007) study, which found many negative compromises in BEE dealings that can kill the spirit of those involved in the deal. He also revealed a great amount of back-stabbing between BEE partners, which is perhaps reinforced by structuring a deal without full participation of BEE parties.

Category B: Processes and methods used to overcome the main challenges. Present results and a past study (Creamer, 2005) are consistent as they identify identical traits for selection of an appropriate and relevant partner for a BEE deal. In the deal mentioned in the present study, for example, a comprehensive and transparent BEE partner selection process was applied to avoid irrelevance of the deal and to identify value-adding partners showing an understanding of the industry, free of conflicts of interest, offering appropriate empowerment credentials, and with a good strategic fit to the company and characteristics complementary to the other parties involved in the transaction.

The findings of the present study regarding the process and challenge of correctly evaluating assets are underlined by the reports of Radebe (2006), who stated that concluding a BEE deal requires creativity, innovation and out-of-the-box thinking. Moreover, Radebe suggests that it is crucial to evaluate correctly the assets that BEE partners are buying. An overpriced asset will be unattractive to prospective buyers, while underpriced assets will punish the seller.

Category C: Sustainability issues. According to Albinski (2007), robustly structured cash flow-based BEE deals are sustainable and deliver value to all stakeholders. Since tested under various economic scenarios and built on appropriate margins of safety, they should ensure that a deal can handle all economic environments without unravelling. The present findings are consistent with Albinski (2007), as the deal leads to establishing an innovative and competitive funding structure based on realistic cash flows to ensure sustainability of the transaction and of Exxaro Limited.

The deal in the present study strategically eliminated the politically connected usual candidates by considering them as unsuitable BEE partners for the Exxaro Limited transaction. This was to broaden the empowerment redistribution opportunities. Findings of the present study disagree with Reddy (Business Map Foundation, 2004), who had previously stated that empowerment, especially in the mining industry, was dominated by small, politically connected elites. This makes sense if the key value-add that the organisation is looking for is in the partner's ability to access a mining licence. In this context highly politically connected partners would probably be the correct strategic choice. This further establishes the fact that while government remains the dominant provider of redistribution opportunities, it is likely that businesses will look at politically connected empowerment partners.

Category D: Positive aspects. Balshaw and Goldberg (2005) observed that a broad-based BEE transformation process has an inherent ability to create distrust within a business that makes it difficult to operate effectively. This is because it stands or falls on the capacity of stakeholders to build trust and foster collaboration. Trust is promoted by addressing conflicts, having a shared vision, establishing suitable communication, decision-making and governance structures, sharing information and avoiding secretiveness by ensuring appropriate sanctions in circumstances where trust has been breached (Balshaw \& Goldberg, 2005). Present findings are parallel with Balshaw and Goldberg's (2005) report, stating that the new deals make tremendous efforts in building trust among various parties for sustainability of the transaction.

According to Mashiatshidi (Business Map Foundation, 2004), good BEE practice is not about entitlement or enrichment, neither is it a prescription for value appropriation without compensation. However, it is one that should not only avoid value destruction, but should be a platform for value creation. A strong correlation was found between the previous study of Mashiatshidi (Business Map Foundation, 2004) and present research. Both found creation of value for all parties involved in the transaction a significant aspect. In 2006 women investment groups and community involvement became more prominent in BBBEE transactions, although women did not always bring sectorspecific experience into a transaction. However they contributed to the broad-based nature of BEE. The present study reports that although it was a challenge to identify and incorporate women's groups and community trusts as BEE investors, it was a significant outcome of the transaction.

Category E: Current issues. According to Chiume and Kingston (2006), introduction of an empowerment shareholder is a complex process, not dissimilar to a typical merger and acquisition transaction. They further state that the process is made more complex by the need to meet the commercial objectives of the company, introducing the empowerment shareholders and also to mitigate the limited financing capacity of the typical black empowerment partner (Chiume \& Kingston, 2006). Complex funding structures are often designed and implemented in order to address both the concerns of the company's existing shareholders regarding potential value leakage and dilution, and the requirements of government and other key stakeholders tasked with advancing broader empowerment objectives (Chiume \& Kingston, 2006). It is in developing a coordinated approach that the role of an investment banker in implementing BEE transactions becomes key (Chiume \& Kingston, 2006). This coordinated approach addresses all of these elements while creating a transaction structure that is sustainable and that results in value creation for both the empowered company and its black empowerment partners. There are parallels between Chiume and Kingston's (2006) report and the present study, both stating that growing the 
newly formed company and creating value for all stakeholders necessary for sustainability was an issue.

The findings of the present study indicate that the merging of cultures, operations and people is still a challenge for Exxaro Limited. However, doing this with success would contribute to the sustainability of the company. These findings are congruent with the findings of Malan and Foulds (Business Map Foundation, 2004), who suggest that the new South African organisations could be successful if an empowerment culture could be adopted, particularly one which emphasises the broad empowerment of its entire workforce. If, however, the organisation's culture and a BEE culture do not fit then newly black-owned business is set for failure.

The present study found that management succession and managing the transition and handover period, between the current leadership of the company and the leadership taking over in late 2007, are significant challenges facing Exxaro Limited. This correlates with the study of Radebe (2006), illustrating in the Johnnic / NEC case study the need for a lead BEE partner, leadership and management succession, as a challenge. Radebe (2006) notes that the original NEC, that acquired a controlling stake in Johnnic, had many participants but no clear leader. Although the empowerment deal failed owing to an inappropriate funding structure, but it also failed because of a lack of leadership (Radebe, 2006). In the absence of a lead BEE partner and leadership there was no coordination and there was nobody to take key investment decisions.

Findings of the present study indicate that managing market expectations is a challenge for Exxaro Limited. This corresponds with the report of Reddy (Business Map Foundation, 2004), who indicates that the empowerment process is a market-driven process. Thus its progress and success will reflect all the machinations, risks and vagaries of the market and will depend upon the following:

\section{- A coherent regulatory environment}

- $\quad$ The coherent alignment of empowerment objectives with criteria used to allocate preferential opportunities

- $\quad$ The strategic intent at an organisational level

- $\quad$ Competitive dynamics at an industry level

- An enabling business culture

- $\quad$ Quality of funding.

The present study indicates skills shortage as a challenge facing Exxaro Limited at present. It also indicates that a skills shortage dilemma is not confined to Exxaro Limited, but is a challenge facing the entire mining industry and the country. The study is found to be consistent with the reports of Hlengani (2006), who states that the failure of the education system to produce enough relevant skilled individuals, including plumbers, toolmakers and engineers, is one of the main reasons that the economic growth of the past few years in South Africa has not reduced unemployment levels.

Category F: Future challenges. In the present study the Exxaro Limited transaction was concluded while the market was in a bullish phase with commodity prices at the top of their cycle; hence the cyclical nature of the market and the reason why commodity prices are a future challenge for the company. The findings of Davenport (2006) indicate that value creation and realisation will be difficult if BEE companies invest in organisations while commodity prices are at the top of the commodity cycle. Present findings are consistent with Davenport's (2006) study. According to Davenport (2006), mining assets and company share prices are too expensive for small black investors. Hence it is not viable for BEE companies to buy into major conglomerates and their various assets, which are at the top of their commodity cycle, and make it much more difficult to realise value on these investments. BEE deals that have been successful and have remained economically viable up to this point are deals that were concluded when commodity prices were at the bottom of the down cycle (Davenport, 2006).

According to Barends (Finweek, 2006), financing remains a problem for all empowerment players and has been thus since the inception of empowerment. Maphisa (Finweek, 2006) points out that cash flow are related to the issue of financing. Empowerment deals tend to be structured over a relatively long period of time and in such a way that any dividends flowing from such investments go towards loan repayments (Finweek, 2006). This means that the BEE partner has no or limited cash flow to finance its operating costs. The findings of Barends (Finweek, 2006) and Maphisa (Finweek, (2006) reiterate the concerns expressed by the respondents of the present study, indicating apprehension regarding the dividend flow to the BEE partners.

Category G: Different options. Cargill (2005) states that companies are tending to favour the approach of identifying a lead BEE investment company, which then becomes responsible for ensuring a broad base of shareholders involved, as a means to manage the alignment. However, the mainstream company tends to abdicate responsibility for ensuring a solid BEE investor grouping, yet will almost invariably carry all the reputational risk should things fall apart (Business Map Foundation, 2004). The present study found that aligning the interests of the various parties is a challenge, and therefore, to have a lead BEE investment company would have helped in the process, hence correlates with the reports of Cargill (2005).

The present findings indicate that during the Exxaro Limited transaction, some uncertainty and ambiguity regarding the requirements of the Broad-Based BEE Act and the Mining Charter surfaced. This was owing to lack of time spent on attaining clarity and a better understanding of the legislation and the associated processes. This correlates with the study by Van der Merwe (Business Map Foundation, 2004) which states that while the enactment of the Empowerment Act is a positive step towards achieving a comprehensive legal framework for the transformation of the South African economy and the equitable distribution of its resources. Yet 
it only puts in place various guidelines and objectives of what this transformation should achieve. It does not, however, set down detailed obligations as to the manner in which such transformation should take place (Business Map Foundation, 2004).

\section{Conclusions and recommendations}

The challenges of broad-based black economic empowerment transactions are the same as those of mergers and acquisitions, wherein the new business model needs to work to produce a return for shareholders. The drive behind a BEE transaction, however, comes from a legislative requirement, and even more so from the potential loss of business than some legal penalties. The penalty in the BBBEE regulation is eventually loss of business. The problem in implementation of BBBEE is that ownership (the merger and acquisition element) only counts for $20 \%$ of the scorecard.

Most engaged in mergers and acquisitions do not realise that, from a BBBEE perspective, there is another $80 \%$ on the scorecard that needs to be complied with.

It is evident from the findings of the present study that some uncertainty and ambiguity exists around BEE legislation and its associated processes. The Act does not provide detailed prescriptions as to the manner in which companies should approach transformation. While the Mining Charter sets out clear objectives for mining organisations, the objectives of BEE legislation are ambiguous and open to varied interpretations. Therefore, mining organisations entering into BEE transactions will have to spend a significant amount of time understanding legislative requirements to ensure compliance.

There is an increased focus on ensuring genuine and sustainable broad-based BEE in South Africa, essentially to implement suitable funding structures that are not superficial fronting arrangements. Many BEE transactions have failed since their inception owing to complex, elaborate and unsustainable funding structures (Fauconnier, 2006). These entail the use of hybrid funding instruments, debt finance, vendor finance and equity investment. The successfully implemented BEE transactions have similarities when scrutinising their funding structures that include the use of SPVS, mezzanine funding, issuing of preference shares, vendor financing, third-party funding, the use of dividend income to service the debt of the BEE investors, and sustainable cash flows.

Present findings indicate that the funding structures based on share price appreciation and those that impose unreasonable conditions on BEE investors are unsustainable and invariably lead to the failure of the transaction. Benchmarking and stress-testing a funding structure and its cash flows under various economic scenarios, and incorporating appropriate margins of safety into the funding structure will ensure that the funding structure copes with various economic environments without unravelling.

The present study avoided the use of the "usual suspects" in the transaction and emphasised the incorporation of broad- based audiences. It nevertheless found difficulties in identifying and incorporating a broad-based audience with the necessary experience and expertise and in achieving alignment between the many interests of the broad-based audiences. Organisations are urged to follow a comprehensive and transparent BEE partner selection process to ensure good governance and to avoid undesirable repercussions.

Although women are increasingly participating in the BBBEE transactions, there are very few women's groups with sufficient experience and expertise to enable them to contribute substantially to these transactions.

Organisations enforce lock-in periods for their BEE partners to prevent the dilution of the organisation's BEE status. This is also in line with government's objective of unencumbered ownership of enterprises by HDI on a sustainable basis. The challenge for the BEE investor lies in accepting the lock-in period and realising that liquidity will only be introduced once the lock-in period has expired.

Interest in BBBEE is divergent. For certain organisations BBBEE is a compliance exercise rather than a strategic imperative. While for certain black people it is a quick way to get rich without consideration of the means they employ. The process of communicating and engaging facilitates the exploration of various options and assists in getting parties onto the same page. Moreover, it assists in gaining an understanding of the expectations, thoughts and perceptions of all the parties involved in such a transaction. It is clear that the success of a BBBEE deal hinges on the ability of stakeholders to build trust and foster collaboration.

Given that the values of organisations centre on survival and best practices, the values of BEE leaders centre on community and social upliftment. Hence for BEE to be successful the challenge lies in bridging the gap between these sets of values and incorporating a comprehensive cultural transformation programme.

The present study suggests that vendor companies and BEE partners should co-develop plans for the BEE transactions. Several vendor companies, especially multinationals, approach potential BEE investors with a predetermined agenda. And if the agenda of the vendor company does not favour the BEE investors, they offer the deal to BEE investors who are willing to accept their predetermined agenda, which may lead to back-stabbing among the BEE investors.

Value creation is a vital part of a BEE transaction. This aspect should receive greater focus than those which may destroy values. Complex funding structures are often designed and implemented to minimise the leakage of value. However, for the existing shareholders involved in the transaction, there is always potential for value leakage. BEE must form part of the overall company strategy in order to realise growth prospects of the organisation and to create sustainable value.

BBBEE deals can be concluded with success within a prevailing bull market where commodity prices are at the 
top of their cycle. Creating a diversified mining company with a sound asset base and good growth prospects could assist in the sustainability of a BEE transaction. Empowerment is a market-driven process and its progress will reflect the intrigues, risks and vagaries of the market. There are no guarantees for the empowerment process. It is clear that BEE investors and empowerment companies will continually have to deal with market expectations.

\section{Limitation and future studies}

Since the present study is limited to the empowerment transactions of the Exxaro Limited case study, it may be useful for future studies to investigate comparable empowerment transactions within other mining industries in as much detail as the present investigation. It might also be useful to investigate and compare empowerment transactions across industries within the South African economy in similar detail to the present study.

The proposed future studies could assist organisations with structuring and implementing BEE transactions more efficiently and cost-effectively. Future studies might also include investigations of BEE transactions as BEE evolves over time. An example of this is the evolution of financial structures during the first, second and current development of BEE. Each development of BEE brings new requirements for BEE participants as well as lessons learnt. Finally, it was difficult for the present study to create a sound theoretical base, owing to lack of empirical studies and literature in the field.

\section{References}

Albinski, I. 2007. 'How to build a BEE deal that lasts', Business Day, 19 March.

Balshaw, T. \& Goldberg, J. 2005. Cracking broad-based black economic empowerment, codes and scorecard unpacked. Cape Town: Human \& Rossouw.

Booysen, L. 2007. 'Barriers to employment equity implementation and retention of blacks in management in South Africa', South African Journal of Labour Relations, 31(1):47-69.

Business Map Foundation. 2003. 'Unpacking the MvelaGold Fields deal'. [online] Available: http://www.businessmap.org.za. Accessed 24 April 2007.

Business Map Foundation. 2004. 'Empowerment 2004. Black ownership: risk or opportunity?' [online] Available: http://www.businessmap.org.za. Accessed: 3 June 2007.

Business Map Foundation. 2006. 'BEE 2006: Charters and deals. [online] Available: http://www.businessmap.org.za. Accessed: November 2006.

Business Map Foundation. 2007. 'BEE 2007: Empowerment and its critic'. [online] Available: http://www.businessmpa.org.za. Accessed: 15 August 2007.
Cargill, J. 1999. 'Empowerment 1999 - A moving experience’. Business Map Foundation, 22 February. [online] Available: http://www.businessmap.org.za. Accessed: 16 January 2007.

Cargill, J. 2005. 'Black corporate ownership: Complex codes can impede change'. In Conflict and governance: Economic transformation: Audit 2005. Cape Town: Institute for Justice and Reconciliation, CT.

Chiume, L. \& Kingston, M.L. 2006. 'The role of an investment bank in broad-based BEE transactions: A banker's perspective', New Agenda. South African Journal of Social and Economic Policy, 22, 25-29.

Creamer, M. 2005. 'Most complex deal in my 22 years. Mining Weekly Online, 16 December. [online] Available: http://www miningweekly.co.za. Accessed: 14 August 2007.

Davenport, J. 2006. 'BEE investor in good position for diversified growth', Mining Weekly Online, 14 April. [online] Available: http://www.miningweekly.co.za. Accessed: 6 June 2007.

Department of Trade and Industry, 2002. 'South Africa's economic transformation: A strategy for broad based black economic empowerment'. [online] Available: www.dti.gov.za.

Department of Trade and Industry, 2004. 'The draft codes of good practice on broad-based black economic empowerment'. [online] Available: www.dti.gov.za.

Du Toit, A., Krugar, A. \& Ponte, S. 2008. 'Deracializing exploitation? Black Economic Empowerment' in the South African wine industry. Journal of Agrarian Change, 8(1), 632.

Fauconnier, C. J. 2006. 'Kumba Resources: Creating South Africa's flagship empowerment company. Can this deal be different?' Speech delivered at the Investing in African Mining Indaba, Cape Town, 7 February.

Finweek. 2006. 'Issues facing BEE partners'. 24 August, 7880 .

Goldwyer, N. 2007. 'SA moves towards empowerment equilibrium', Mining Weekly Online. [online] Available: http://www miningweekly.co.za. Accessed: 2 May 2007.

Gray, K. \& Karp, R. 1993. 'An experiment in exporting U.S. value abroad: The Sullivan Principles and South Africa', The International Journal of Sociology and Social Policy, 13(7), 1-14.

Grobler, J. 2006. 'A brief study of the codes and charters', Top Women in Business and Government, 3, 30-31.

Hamann R., Khagram, S. \& Rohan, S. 2008. 'South Africa’s charter approach to post-apartheid economic transformation: Collaborative governance or hardball bargaining?', Journal of Southern African Studies, 34(1), 20-37. 
Hlengani, T. 2006. 'Employment equity and skills: Can corporate SA win the skills game?' Financial Mail, 10 March.

Iheduru, O. 2004. 'Black economic power and nationbuilding in post-apartheid South Africa' Journal of Modern African Studies, 42(1),1-30.

Jack, V. 2006. 'Aligning different interests is a key for a code of conduct', Business Report, 23 April.

Jack, V. 2007. 'Compromise in BEE is a sign of hunger economics’, Business Report, 22 June.

Kovacevic, N. 2007. 'Righting wrongs. Affirmative action in South Africa', Harvard International Review, Spring: 6.

Kumba Resources Limited. 2006. [online] Available: http://www.kumbaresources.com. Accessed: 30 October 2006.

Radebe, S. 2006. 'Model for equity needs a rethink', Financial Mail, 10 March.

Republic of South Africa. 2002a. Broad-based Socioeconomic Empowerment Charter for the South African Mining Industry. Pretoria: Department of Minerals and Energy.

Republic of South Africa. 2007a. Broad-based Black Economic Empowerment Act: The Codes of Good Practice. Pretoria: Department of Trade and Industry.

Republic of South Africa. 2007b. Scorecard for the Broadbased Socio-economic Empowerment Charter for the South African Mining Industry. Pretoria: Department of Minerals and Energy.

Ryan, B. 2006. 'Not the usual suspects', Financial Mail, 10 March.

Slaughter, B. 1999. 'South Africa: the fraud of "black empowerment”'. World Socialist Website (http://www.wsws.org).

Sono, T. 1999. 'Empower individuals, not groups', Finance Week 15, January:21.

Turok, B. 2000. 'Black economic empowerment serving elite or mass interests?', New Agenda, South African Journal of Social and Economic Policy, Winter:4-7.

Turok, B. 2006. 'BEE transactions and their unintended consequences', New Agenda. South African Journal of Social and Economic Policy, 22:59-64.

Weber, R.P. 1990. Basic content analysis. $2^{\text {nd }}$ edition. Newbury Park, California: Sage Publications. 